\title{
Modeling heat transfer process in soils
}

\author{
Ian Ofrikhter ${ }^{1}$, Alexander Zaharov ${ }^{1}$, Andrey Ponomaryov ${ }^{1}$ and Natalia Likhacheva ${ }^{2}$ \\ ${ }^{1}$ PNRPU, Construction operations and Geotechnics Department, 614990, Perm, Russia \\ ${ }^{2}$ PNRPU, Applied Mathematics Department, 614990, Perm, Russia
}

\begin{abstract}
In this paper, a new model is presented for calculating the thermal conductivity of soils, and the main provisions for the derivation of analytical formulas are given. The presented model allows taking into account the density, moisture content and temperature of the soil base. The technique presented in the paper makes it possible to dispense with laborious experiments to estimate the thermal conductivity of the soil. The method of analytical calculation is step by step presented in the paper. Two variants of using the method are proposed:

1) Less accurate method, for preliminary evaluation, without the need to take probe and conduct experiments.

2) More accurate method, with at least one experiment with a disturbed or undisturbed sample.

The results of comparison of calculated values of thermal conductivity and experimental data are presented.
\end{abstract}

\section{Introduction}

Ground source heat pumps are becoming more common. For their correct design, it is necessary to know the thermal conductivity of the soil. To date, there are many methods for determining the thermal conductivity of the soil. However, the universal model that is applicable to all types of soil does not still exist. There are three main groups of methods: empirical, mathematical [1] and mixed. The most common in practice are empirical methods [2-6]. However, they are often developed and applicable for a narrow group of soils and for specific humidity ranges. In addition, many of them require experiments, which does not allow for an approximate assessment of the thermal conductivity of the soil according to its physical characteristics [7-8].

From the mixed methods of calculating the thermal conductivity, one can single out the works of the following authors [9-12].

The basic approach in the mixed methods is that in a unit volume there are geometric elements with volumes corresponding to the volumes of the mineral part, air, and water in the soil. The problem, in this case, occurs when trying to determine the most appropriate geometry for the elements of the soil and their relative position.

The limited applicability of existing models, as well as their weak correlation with experimental data, make the question of calculating the thermal conductivity of soils still relevant. 


\section{Methods}

A soil base considered as a three-phase system consisting of air, water, and the mineral part. Heat transfer due to heat and mass transfer by groundwater is not taken into account. The proposed model is a cube in which two spheres truncated by the faces of the cube are located (Fig. 1).

The central sphere simulates the volume of the mineral part of the soil. The volume of water is located in the space between the surfaces of the first and second truncated spheres. The rest, bounded by the edges of a single cube, is air. The direction of heat flow is taken parallel to the Z-axis.

Radii $R_{s}$ and $R_{w}$ limit the volume of the mineral part and water, respectively. The volume of the truncated spheres can be expressed in terms of the porosity of the soil $n$ and the coefficient of water saturation $S_{r}$. From the volume of truncated spheres, approximate equations for $R_{s}(1)$ and $R_{w}(2)$ obtained.

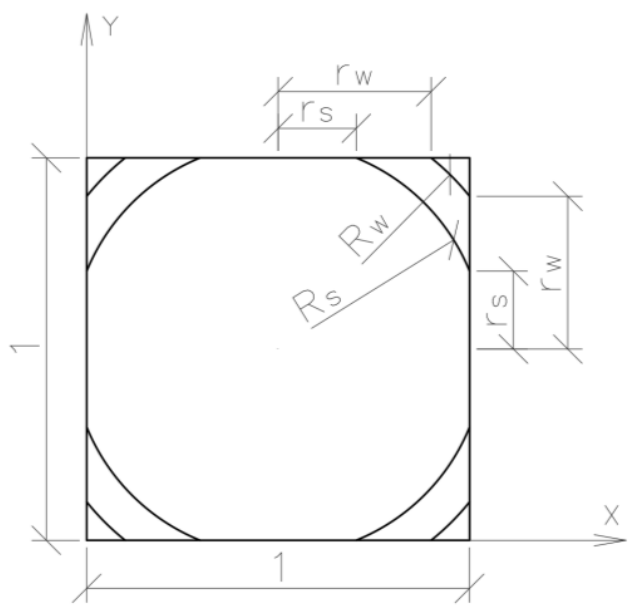

Fig. 1. Model for calculation of heat transfer in soils.

$$
\begin{gathered}
R_{s}=120,7 n^{6}-207,9 n^{5}+144,6 n^{4}-52,55 n^{3}+10,97 n^{2}-1,73 n+0,755 \\
R_{w}=120,7 a_{1}^{6}-207,9 a_{1}^{5}+144,6 a_{1}^{4}-52,55 a_{1}^{3}+10,97 a_{1}^{2}-1,73 a+0,755 \\
a_{1}=n-n \cdot S_{r}
\end{gathered}
$$

The heat flux is taken along the direction of the Z-axis. The total heat flux $Q_{t o t}$ is divided into several $Q_{i}$. Each heat flux $Q_{i}$ passes through a different combination of soil elements. Having carried out a diagonal section, one can determine that there are five "routes" of heat flow $Q_{1-5}$ (Fig.2). 


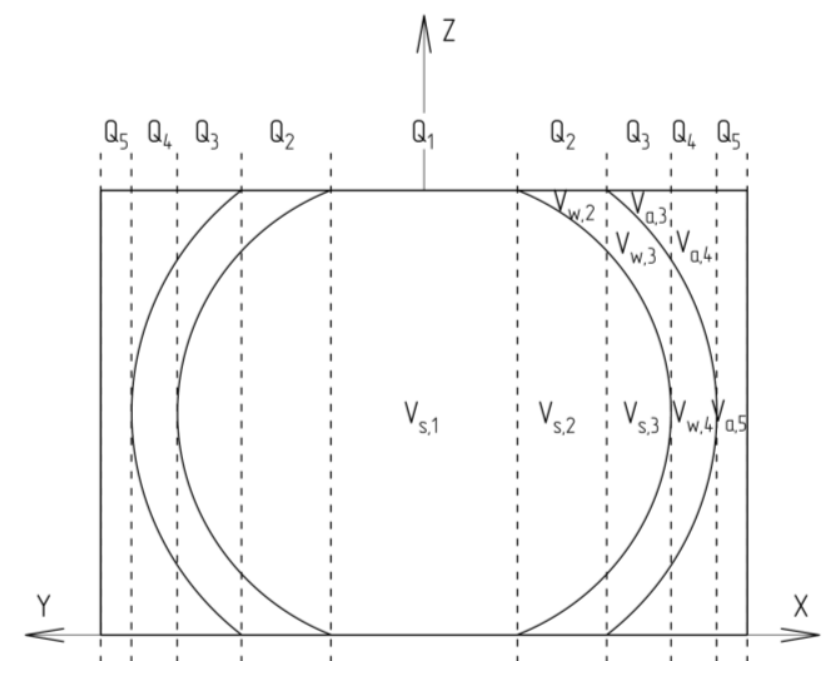

Fig. 2. Diagonal cut

The effective thermal conductivity of the soil can be calculated by the formula:

$$
\lambda_{\text {eff }}=\frac{Q_{1}+Q_{2}+Q_{3}+Q_{4}+Q_{5}}{\Delta T \cdot l}
$$

$l$ is the length of a unit cube; $\Delta T$ - temperature gradient. The magnitude of the heat flux $Q_{i}$ was calculated by a known formula for a multi-layered wall. The wall thickness is taken as the volume $V_{i}$ divided by the heat flux area $S_{i}$. Then the heat flux formula is written in the general form (5).

$$
Q=S^{2} \cdot \frac{\Delta T}{\sum_{i+1}^{n} \frac{V_{i}}{\lambda_{i}}}, W
$$

\section{Results}

As a result, a formula for calculating the effective thermal conductivity was obtained (6).

$$
\lambda_{\text {eff }}=\frac{S_{1}^{2}}{\frac{V_{s, 1}}{\lambda_{s}}}+\frac{S_{2}^{2}}{\frac{V_{s, 2}}{\lambda_{s}}+\frac{V_{\mathrm{w}, 2}}{\lambda_{w}}}+\frac{S_{3}^{2}}{\frac{V_{s, 3}}{\lambda_{s}}+\frac{V_{w, 3}}{\lambda_{w}}+\frac{V_{a, 3}}{\lambda_{a}}}+\frac{S_{4}^{2}}{\frac{V_{\mathrm{w}, 2}}{\lambda_{w}}+\frac{V_{a, 4}}{\lambda_{a}}}+\frac{S_{5}^{2}}{\frac{V_{s, 5}}{\lambda_{s}}}, \frac{W}{m \circ C}
$$

$\lambda_{s}$ is the thermal conductivity of the mineral part; $\lambda_{w}$ - thermal conductivity of water; $\lambda_{a}$ - thermal conductivity of air. The thermal conductivity of water and air is determined depending on the temperature by the known formulas:

$$
\begin{gathered}
\lambda_{w}=0,552+2,34 \cdot 10^{-3} T-1,1 \cdot 10^{-5} \cdot T^{2} \\
\lambda_{a}=0,0237+0,000064 \cdot \mathrm{T}
\end{gathered}
$$


The parameters of the formula 6 can be founded from the equations presented in table 1 . $V_{w, 4}$ should be calculated numerically. While $R_{s}$ and $R_{w}$ found by equations $(1,2)$ are limited, there are limits of porosity and water saturation coefficient for which the model is applicable $(9,10)$.

Table 1.Equations for calculating parameters

\begin{tabular}{|c|c|}
\hline Parameter & Equation \\
\hline$S_{1}$ & $\pi\left(\mathrm{R}_{s}^{2}-0,25\right)$ \\
\hline$S_{2}$ & $\pi\left(\mathrm{R}_{w}^{2}-R_{s}^{2}\right)$ \\
\hline$S_{3}$ & $1-S_{1}-S_{2}-S_{4}-S_{5}$ \\
\hline$S_{4}$ & $1-\pi R_{s}^{2}+4 \cdot\left(R_{s}^{2} \cdot \arccos \left(\frac{0,5}{R_{s}}\right)-0,5 \cdot \sqrt{R_{s}^{2}-0,25}\right)-S_{5}$ \\
\hline$S_{5}$ & $1-\pi R_{w}^{2}+4 \cdot\left(R_{s}^{2} \cdot \arccos \left(\frac{0,5}{R_{w}}\right)-0,5 \cdot \sqrt{R_{w}^{2}-0,25}\right)$ \\
\hline$V_{s, 1}$ & $S_{1}$ \\
\hline$V_{s, 2}$ & $\frac{1}{6} \pi\left(1-8\left(R_{s}^{2}-R_{w}^{2}+0,25\right)^{\frac{2}{3}}\right.$ \\
\hline$V_{w, 2}$ & $S_{2}-V_{s, 2}$ \\
\hline$V_{s, 3}$ & $1-n-V_{s, 1}-V_{s, 2}$ \\
\hline$V_{w, 3}$ & $n S_{r}-V_{\mathrm{w}, 2}-V_{\mathrm{w}, 4}$ \\
\hline$V_{a, 3}$ & $n \cdot\left(1-S_{r}\right)-V_{a, 4}-V_{a, 5}$ \\
\hline$V_{w, 4}$ & $\frac{16}{3} \cdot\left(\left(R_{w}^{2}-R_{s}^{2}\right)^{\frac{3}{2}} \cdot\left(\frac{\pi}{4}-\arccos \left(\frac{0,5}{R_{w}}\right)\right)-\int_{\arccos \frac{0,5}{R_{s}}}^{\arccos \frac{0,5}{R_{w}}}\left(R_{w}^{2}-\frac{0,25}{\cos ^{2} \varphi}\right)^{\frac{3}{2}} d \varphi\right)$ \\
\hline$V_{a, 4}$ & $S_{4}-V_{w, 4}$ \\
\hline$V_{a, 1}$ & $S_{5}$ \\
\hline \multicolumn{2}{|r|}{$0,0349 \leq n \leq 0,4764$} \\
\hline \multicolumn{2}{|r|}{$S_{r} \leq 1-\frac{0,0349}{n}$} \\
\hline
\end{tabular}

In the case when the coefficient of water saturation exceeds the value indicated in the inequality, the influence of air in the soil on its thermal conductivity is insignificant, and soil can be accepted as saturated. The coefficient of water saturation $S_{r}$ and the porosity of the soil $n$ is determined by the results of engineering geological surveys. When designing ground heat exchangers, the temperature of the soil, when designing systems of ground heat exchangers can be taken about 279 - 285 degrees Kelvin [14], which will not make a serious error.

The thermal conductivity of the mineral part can be determined from the results of the single experiment. You can use the sample, both selected in the field and formed in the laboratory from the required mineral part. It is important to note that the sample may have an impaired structure, the moisture and density of the sample may not be equal to the characteristics of the soil base. 


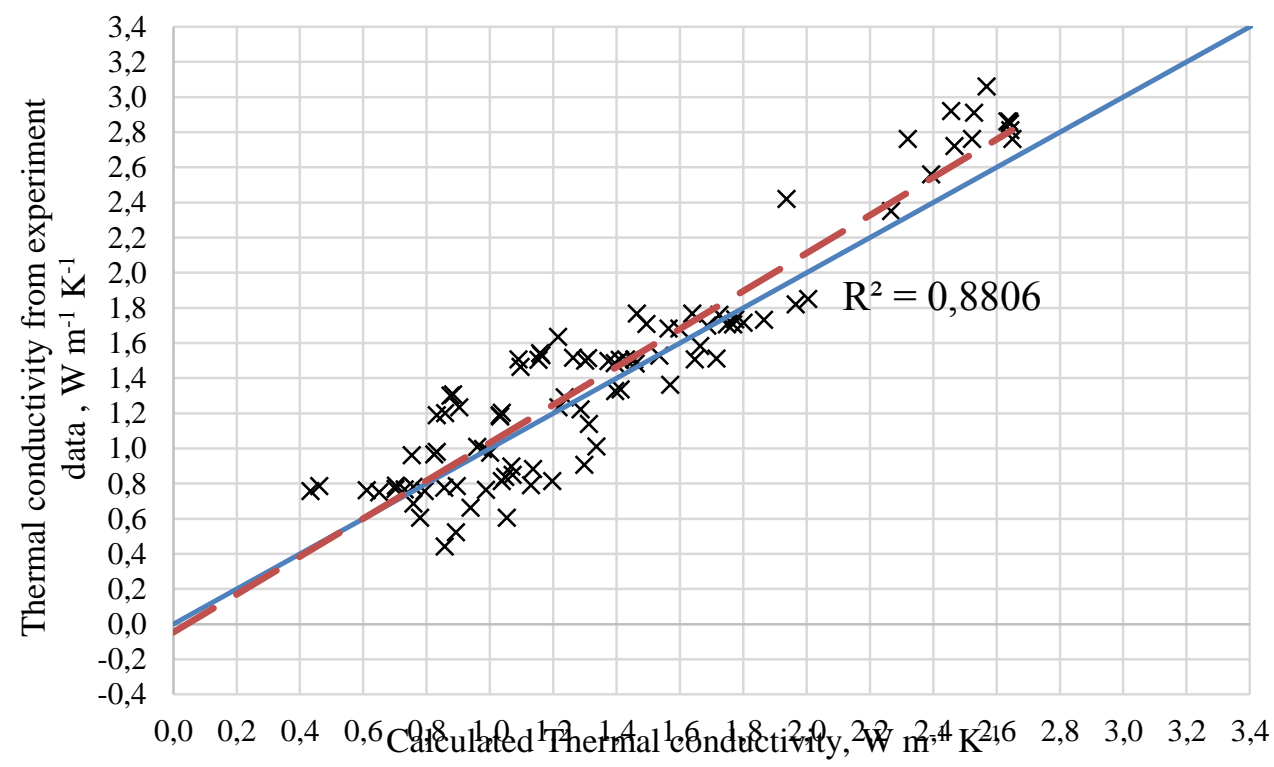

Fig. 3. Comparison of calculated and experimental values of thermal conductivity for clay soil

To determine the thermal conductivity of the mineral part of a soil sample, it is necessary to measure the thermal conductivity and determine the temperature, porosity, and coefficient of water saturation of the sample in any available way. Further, the values in formula 6 are selected so that it coincides with the value obtained from the experiment.

In addition, to determine the thermal conductivity of the mineral part of the soil, existing recommendations can be used [15].

For testing the proposed analytical model, thermal conductivity of the cohesive soil calculated by this method was compared to the experimental data obtained in the laboratory (Fig 3).

Samples of cohesive soil with a diameter of $100 \mathrm{~mm}$ and a height of at least $120 \mathrm{~mm}$ were tested. In addition, experimental data from various authors was used $[16,17]$. Variation of values can be significant, however, with a larger number of definitions, the convergence of the computational model and experimental data is quite high.

\section{Conclusions}

An analytical model has been developed for estimating the thermal conductivity of a soil from known physical characteristics. The presented model is currently tested for thawed soil samples, and shows a good correlation with experimental data.

\section{References}

1. Haigh Stuart. Thermal conductivity of sands // Géotechnique. - 2012. - Vol. 62. pp.617-625 617-625. DOI: 10.1680/geot.11.P.043.

2. Abu-Hamdeh, N \& Reeder, Randall. Soil thermal conductivity: Effects of density, moisture, salt concentration, and organic matte // Soil Science Society of America Journal. - 2000. - Vol. 64, No.4. - pp. 1285-1290. DOI: 10.2136/sssaj2000.6441285x. 
3. Campbell, G., Jungbauer Jr, J., Bidlake, W., Hungerford, R., 1994. Predicting the effect of temperature on soil thermal conductivity // Soil Science. - 1994. - Vol. 5, No.158. pp. 307-313.

4. Johansen, O. Thermal Conductivity of Soils and Rocks // Proceedings of the Sixth International Congress of the Foundation Francaise d'Etudes Nordigues. - 1975. - vol. 2. - pp. 407-420.

5. Ning Lu, Yi Dong. Closed-Form Equation for Thermal Conductivity of Unsaturated Soils at Room Temperature // Journal of Geotechnical and Geoenvironmental Engineering. - 2015. - Vol.141,No. 6. Doi: 10.1061/(ASCE)GT.1943-5606.0001295.

6. Yili Lu, Robert Horton, Tusheng Ren. An Empirical Model for Estimating Soil Thermal Conductivity from Texture, Water Content, and Bulk Density // Soil Science Society of America Journal. - 2014. - Vol.78, No. 6. - pp.1876-1868. DOI: 10.2136/sssaj2014.05.0218.

7. Dong Yi, S. McCartney, John Lu, Ning. Critical Review of Thermal Conductivity Models for Unsaturated Soils // Geotechnical and Geological Engineering. - 2015. Vol. 33. - pp. 207-221. DOI: 10.1007/s10706-015-9843-2.

8. Nagy Balázs. (2014). Comparison of Approximate Soil Thermal Conductivity Calculations with Laboratory Measurements and New Estimation Methods for Sandy Clayey Silt // Advanced Materials Research. - 2014. - vol.1041. - pp. 281-287. DOI: 10.4028/www.scientific.net/AMR.1041.281

9. S. Mickley. The Thermal Conductivity of Moist Soil. Transactions of the American Institute of Electrical Engineers. - 1951. - vol. 70, No.2. - pp. 1789-1797. DOI: 10.1109/T-AIEE.1951.5060631

10. Woodside W, Messmer JH. (1961). Thermal conductivity of porous media. I. Unconsolidated sands // J Appl Phys. - 1961. - Vol. 32. - pp.1688-1699.

11. McGaw R. Heat conduction in saturated granular materials // Highway Research Board Special Report. - 1969. - Vol.103. - pp. 114-131.

12. Gori F., Corasaniti S. Theoretical prediction of the soil thermal conductivity at moderately high temperatures // J Heat Transf Trans Asme. - 2002. - Vol.124,No. 6. pp. 1001-1008.

13. Robert P. Ewing, Robert Horton. Thermal conductivity of a cubic lattice of spheres with capillary bridges.

14. A. Zakharov, A. Ponomarev. Research soil temperature fields in perm // PNRPU Construction and Architecture Bulletin. - 2015. - no. 4. - pp. 103-112. DOI: 10.15593/2224-9826/2015.4.08.

15. Peters-Lidard, C. D., Blackburn, E., Liang X.; Wood, E. F., The effect of Soil Thermal Conductivity Parameterization on Surface Energy Fluxes and Temperatures // Journal of the Atmospheric Sciences. - 1998. - Vol.55, No. 7. - pp.1209-1224.

16. Tetiana Nikiforova, Mykola Savytskyi, Karim Limam, Walter Bosschaerts, Rafik Belarbi. Methods and Results of Experimental Researches of Thermal Conductivity of Soils, Energy Procedia. - 2013. - vol. 42. - pp. 775-783.doi: org/10.1016/j.egypro.2013.12.034.

17. Bing tong, Zhiqiu Gao, Robert Horton, Yubin Li. An Empirical Model for Estimating Soil Thermal Conductivity from Soil Water Content and Porosity // DOI: 10.1175/JHMD-15-0119.1. 